\title{
High Efficiency Step-Down Flyback Converter Using Coaxial Cable Coupled-Inductor
}

\author{
Do-Hyun Kim* and Joung-Hu Park ${ }^{\dagger}$ \\ ${ }^{\dagger *}$ Dept. of Electrical Engineering, Soongsil University, Seoul, Korea
}

\begin{abstract}
This paper proposes a high efficiency step-down flyback converter using a coaxial-cable coupled-inductor which has a higher primary-secondary flux linkage than sandwich winding transformers. The structure of the two-winding coaxial cable transformer is described, and the coupling coefficient of the coaxial cable transformer and that of a sandwich winding transformer are compared. A circuit model of the proposed transformer is also obtained from the frequency-response curves of the secondary short-circuit and of the secondary open-circuit. Finally, the performance of the proposed transformer is validated by the experimental results from a $35 \mathrm{~W}$ single-output flyback converter prototype. In addition, the proposed two-winding coaxial transformer is extended to a multiple winding coaxial application. For the performance evaluation of the extended version, $35 \mathrm{~W}$ multi-output hardware prototype of the DC-DC flyback converter was tested.
\end{abstract}

Key words: Coaxial winding, Coupled-inductor, Flyback converter, High efficiency, Multi-output

\section{INTRODUCTION}

The flyback converter is one of the most widely used topologies in DC-DC power conversion applications because of the low cost due to its relatively-simple circuit structure as well as the high reliability due to its electrical isolation, etc. Recently, the flyback converter topology has been expanded to some new engineering fields such as high-step-up flyback inverters for power-conditioning systems in renewable energy sources, power conversion circuits for charge-balance in battery management systems, and so on [1].

One of the most important factors in the power efficiency of flyback converters is the isolation transformer (coupledinductor). Even though power losses in the main switch and diode are worth considering, that of the transformer is one of the dominant factors in terms of efficiency for flyback converters. In fact, reducing the leakage inductance of the transformer is extremely important to increasing the efficiency of the flyback converter. Generally, conventional converters employ sandwich winding methods to reduce the flux leakage of the transformer. Fig. 1 shows an example of the sandwich winding structure [2]. However, the sandwich

Manuscript received Jul. 11, 2012; revised Jan. 18, 2013

Recommended for publication by Associate Editor Honnyong Cha

†Corresponding Author: wait4u@ssu.ac.kr

Tel: +82-2-828-7269, Fax: +82-2-817-7961, Soongsil University

*Dept. of Electrical Engineering, Soongsil University, Korea winding technique is limited by the transformer's coupling coefficient due to the winding-to-winding distance in the winding layout of the half-primary, secondary, and the other half-primary stacking structures. Therefore, a totally-different winding method is necessary for the enhancement of the flux linkage between the windings in order to increase the efficiency of the flyback converter [3]-[15].

This paper proposes a coaxial-cable transformer which has higher degree of coupling coefficient than sandwich winding transformers. 'Coaxial' means that a couple of windings share the axis of the round-shaped conductors. From this geometry, the magnetic flux generated by the current conduction around the windings can be almost perfectly coupled to each other. Using the core geometry, a flyback transformer as a coaxial-cabled coupled-inductor can be made to operate like an ideal transformer from the perspective of the power electronics theory [16].

The remainder of this study is organized as follows. Section II presents the coupling measurement and circuit modeling of the coaxial cable transformer. Section III compares the experimental results of a $35 \mathrm{~W}$ single-output hardware prototype with coaxial cable and another one with sandwich winding. In addition, a comparison of the experimental results from a $35 \mathrm{~W}$ multi-output hardware prototype between a three-winding coaxial cable transformer and a three-winding sandwich transformer are presented in Section IV. Finally, the conclusions are given in Section V. 


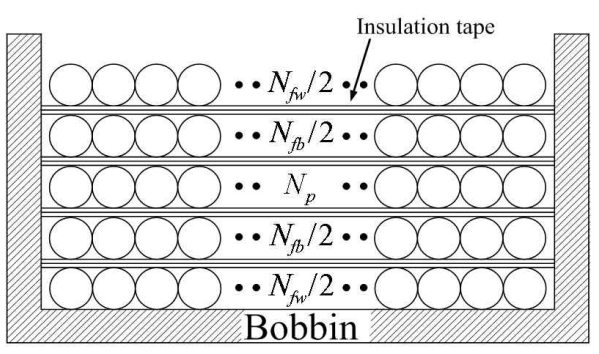

Fig. 1 An example of conventional sandwich winding layout. Primary winding $\left(\mathrm{N}_{\mathrm{p}}\right)$ is sandwiched between other half-and-half layers $\left(\mathrm{N}_{\mathrm{fb}}, \mathrm{N}_{\mathrm{fw}}\right)$ [2].

\section{COAXIAL CABLE TRANSFORMER}

Generally, a transformer's coupling efficient is influenced by the distance between the primary and secondary winding coils. Currently, sandwich winding is considered as the main solution for making a highly-coupled transformer. But the sandwich method has some limitation in increasing the magnetic flux linkage between primary and secondary winding due to its inherent layer-by-layer structure. Thus this paper proposes an improved winding method to increase the degree of the transformer's coupling. This section presents the parameter measurement details of the hardware device. It also suggests a circuit model for the coaxial transformer from the frequency response analysis [3].

\section{A. Single-Output Coaxial Cable Transformer}

Single-output coaxial-cabled transformer is made of a couple of strands of high-voltage winding coil and a lowvoltage winding coil which fully covers the high-voltage coils. From this structure, the high voltage side becomes the inner conductor and the other one is the outer conductor. Then, the multiple strands of the high-voltage winding coils are connected in series at the extremity. Fig. 2 shows a crosssection of a coaxial cable. Since general step-down converters have high voltage windings in the primary side, the primary becomes the inner conductors, as shown in the figure.

The distributions of the magnetic flux amplitude and the direction both in a sandwich winding transformer and in a coaxial winding transformer are calculated using Finite Element Method (FEM) analysis (COMSOL software), and the derivation results are shown in Fig. 3. ' $\mathrm{P}$ ' means the primary winding, ' $\mathrm{S}$ ' means the secondary winding, and the arrow refers to the flux. In Fig. 3(a), the secondary fluxes around the coil are not shared with the primary. On the other hand, in Fig. 3(b), all of the secondary fluxes encircle the primary winding, which contributes to the higher flux linkage. The proximity between the two coils also contributes to the high coupling coefficient. However, due to this proximity, there is also an increase in the inter-winding parasitic

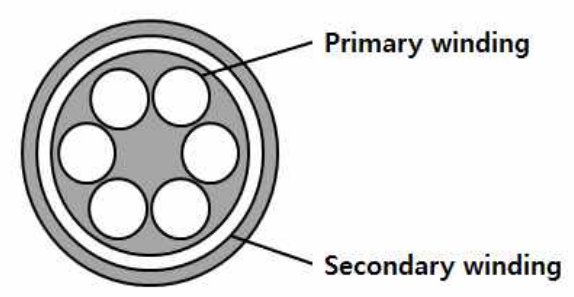

Fig. 2. Cross section of the coaxial cable.

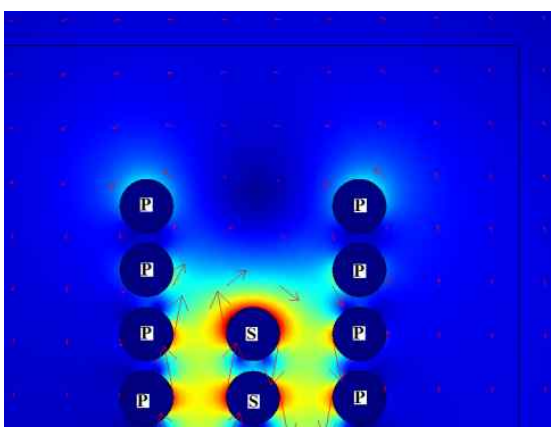

(a) Sandwich winding.

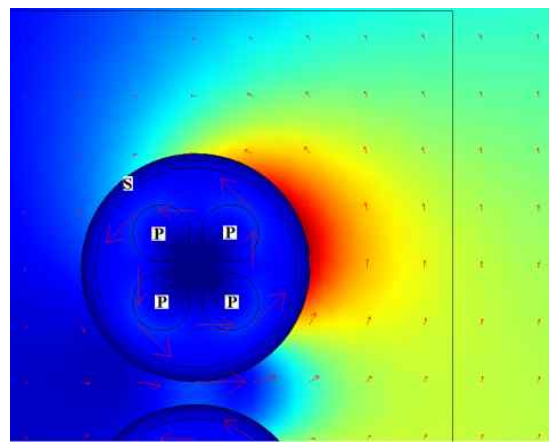

(b) Coaxial cable.

Fig. 3 Magnetic field simulation using COMSOL for checking the magnetic flux distribution of a sandwich and a coaxial cable transformer (P: primary winding, S: secondary).

capacitances which lead to a low dynamic response when a transient happens.

Fig. 4 shows the realized sandwich winding transformer and coaxial cable. The sandwich winding transformer is made of enameled wires (primary 210 turns and secondary 35 turns). A PC40 ferrite core (TDK Co.) is used, because the sandwich winding typically has an optimized coupling coefficient with a bobbin-equipped ferrite magnetic core. On the other hand, the coaxial cable transformer utilized a $\mathrm{CH} 270125$ toroidal core as the worst case, where it is hard to make a high inter-winding flux coupling for the same operating condition.

To compare the coupling coefficients, a two-winding transformer was implemented with each of the winding methods. Calculation of the coupling is done with the following equations [17]: 


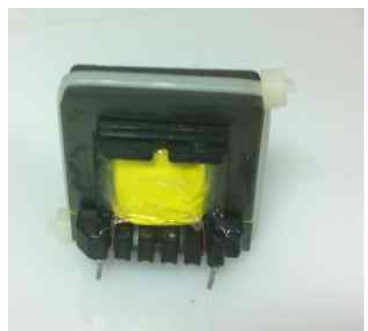

(a) Sandwich winding.

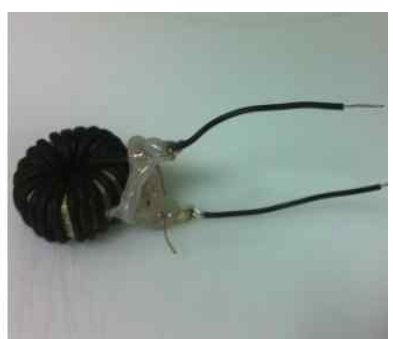

(b) coaxial cable.
Fig. 4 Sandwich and coaxial cable transformer.

$$
k_{12}=\frac{L_{12}}{\sqrt{L_{1} L_{2}}}=\frac{L_{a d d}-L_{o p p}}{4 \sqrt{L_{1} L_{2}}}
$$

where $k_{12}$ is the constant of primary-secondary coupling, $L_{1}$ is the primary inductance, $L_{2}$ is the secondary inductance, $L_{a d d}$ is the series-adding inductance and $L_{o p p}$ is the seriesopposing inductance.

The coupling coefficient of the transformer is measured with eq. (1). The sandwich winding transformer is 0.9897505 and the coaxial cable transformer is 0.9999448 . From these results, it can be seen that the coaxial cable transformer has a flux linkage performance that is superior to that of the sandwich winding transformer.

\section{B. Transformer Modeling}

Fig. 5 shows an example of commonly-used models for the analysis of the proposed two-winding transformer. On the primary side, the winding resistance is represented by $R_{p}$, the leakage inductance by $\mathrm{L}_{\mathrm{lk} 1}$, the magnetizing inductance by $\mathrm{L}_{\mathrm{m}}$, and the winding capacitance by $\mathrm{C}_{\mathrm{m}}$. The secondary winding resistance is $R_{s}$, and the leakage inductance is $L_{1 k 2}$. The modeling process is dependent on the primary-side impedance measurements with the open-circuit secondary and the shortcircuit secondary [18-19]. HP4194 network analyzer was used for the impedance measurements of the coaxial transformer. The frequency-response range is from $100 \mathrm{~Hz}$ to $40 \mathrm{MHz}$. Fig. 6 shows the two primary impedance curves under the conditions of the secondary-opened and the short-circuited. From the comparison of the circuit model with the secondaryopen curve shown in Fig. 6(a), information on the primary resistance, the magnetizing inductance, and the winding capacitance are obtained (especially from the magnitude).

First, the magnitude and phase of the primary impedance are measured under two operating frequencies such as:

$$
\left|\mathrm{Z}_{\text {open }}\right|=33.4 \Omega(1.02 \mathrm{kHz}), 99.6 \Omega(10.06 \mathrm{kHz})
$$

In this region, since the winding resistance $R_{p}$ and the magnetizing inductance $\mathrm{L}_{\mathrm{m}}$ work primarily on the impedance parameter, the parameters are calculated as follows:

$$
\mathrm{R}_{\mathrm{p}}=885 \mathrm{~m} \Omega
$$

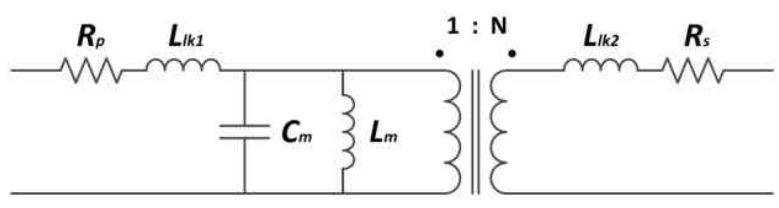

$$
\mathrm{L}_{\mathrm{m}}=5.2 \mathrm{mH} \text {. }
$$

Fig. 5. Equivalent circuit model used for the 2-winding coaxial transformer.

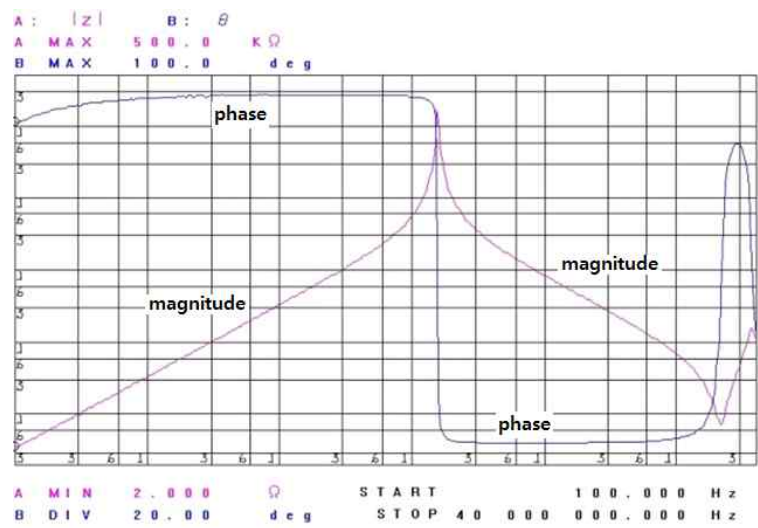

(a) Measurement with open-circuited secondary.

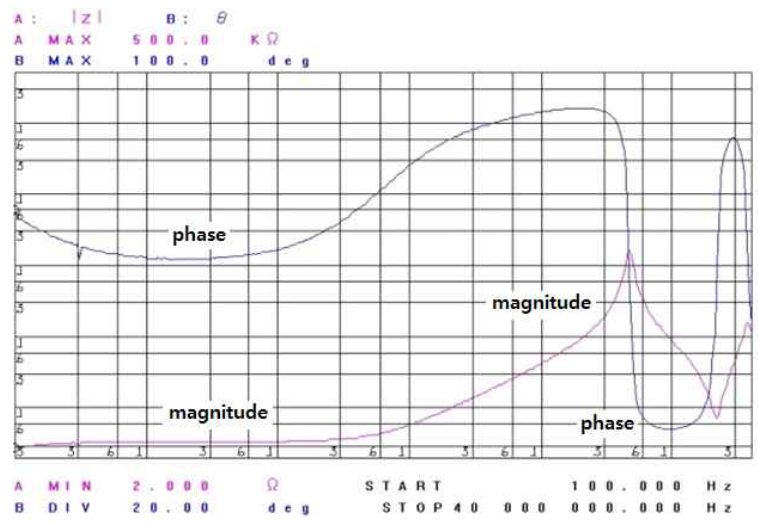

(b) Measurement with short-circuited secondary.

Fig. 6. Coaxial transformer's primary impedance measurements under both of the secondary open-circuited and short-circuited conditions.

In addition, the resonant frequency is:

$$
\mathrm{f}_{\mathrm{r} 1}=\frac{1}{2 \pi \sqrt{\mathrm{L}_{\mathrm{m}} \mathrm{C}_{\mathrm{m}}}}=161.131 \mathrm{kHz}
$$

From this data, the winding capacitance can be calculated as:

$$
\mathrm{C}_{\mathrm{m}}=0.19 \mathrm{nF} \text {. }
$$

The second series-resonant frequency is:

$$
\mathrm{f}_{\mathrm{r} 2}=\frac{1}{2 \pi \sqrt{\mathrm{L}_{\mathrm{k} 1} \mathrm{C}_{\mathrm{m}}}}=21.675 \mathrm{MHz} .
$$

Then, the leakage inductance is:

$$
\mathrm{L}_{\mathrm{k} 1}=0.287 \mu \mathrm{H} \text {. }
$$


TABLE I.

Key PARAMETER OF COAXIAL TRANSFormer

\begin{tabular}{|c|c||c|c|}
\hline $\mathrm{L}_{\mathrm{m}}$ & $5.2 \mathrm{mH}$ & $\mathrm{R}_{\mathrm{p}}$ & $885 \mathrm{~m} \Omega$ \\
\hline $\mathrm{L}_{\mathrm{lk} 1}$ & $0.287 \mathrm{uH}$ & $\mathrm{R}_{\mathrm{s}}$ & $45 \mathrm{~m} \Omega$ \\
\hline $\mathrm{L}_{\mathrm{lk} 2}$ & $0.157 \mathrm{uH}$ & $\mathrm{N}$ & 0.1667 \\
\hline $\mathrm{C}_{\mathrm{m}}$ & $0.19 \mathrm{nF}$ & Coupling k & $>99.99 \%$ \\
\hline
\end{tabular}

Likewise, the other parameters can be calculated from the short-circuit measurement. Fig. 6(b) shows the measurement results. The curves contain the total resistance of the primary and the reflected-secondary one in the low frequency region. At frequencies above $10 \mathrm{kHz}$, the impedance rises due to the leakage inductor impedance. However, for more accurate parameter derivation, we need to separate out the real and imaginary parts to consider each of the contribution of these elements.

First, the magnitude and phase of the primary impedance are measured under two operating frequencies such as:

$\left|Z_{\text {short }}\right|=13.64 \Omega(297.35 \mathrm{kHz}), 42.59 \Omega(1.01 \mathrm{MHz})$.

In this region, since the total winding resistance and the reflected leakage inductance work primarily on the impedance graph, the parameters are calculated as follows:

$$
\begin{gathered}
\mathrm{R}_{\mathrm{s}}=45 \mathrm{~m} \Omega \\
\mathrm{L}_{\mathrm{k} 2} / \mathrm{N}^{2}=5.652 \mu \mathrm{H}
\end{gathered}
$$

Therefore, the secondary inductance is:

$$
\mathrm{L}_{\mathrm{k} 2}=0.157 \mu \mathrm{H}
$$

These equivalent circuit parameters describe the main characteristics of the transformer efficiently. For example, the resistances have a critical effect on the power efficiency. In addition, the leakage inductances cause voltage spikes on the switching devices, which are essentially considered to select the device part number or to design an effective snubber circuit. From the circuit model, the analysis can be performed to understand the operating principles and to derive design guidelines for various converter topologies employing this coaxial-winding transformer. The main parameters of the coaxial transformer are summarized in Table I.

\section{SINGLE-OUtPUT FLYBACK CONVERTER}

\section{A. Leakage Inductance}

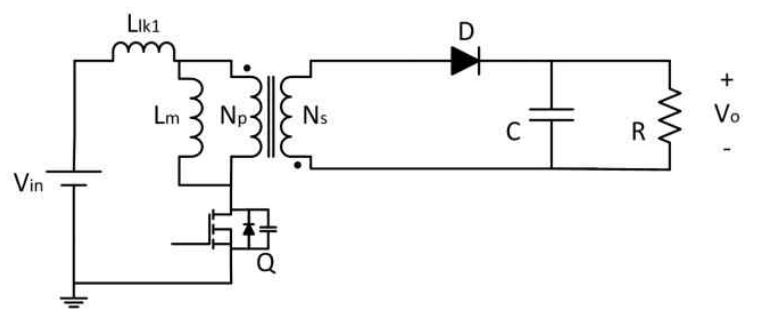

Fig. 7. Circuit diagram of the single-output flyback converter.

TABLE II.

Key Parameters of Flyback CONVERTer

\begin{tabular}{|c|c|c|}
\hline \hline Symbol & $\begin{array}{c}\text { Parameter } \\
\text { (part number) }\end{array}$ & Spec. \\
\hline \hline$V_{\boldsymbol{i}}$ & Input voltage & $40-300 \mathrm{~V}_{\mathrm{DC}}$ \\
\hline$V_{\text {out }}$ & Output voltage & $15 \mathrm{~V}_{\mathrm{DC}}$ \\
\hline$P_{\text {out }}$ & Output power & $35 \mathrm{~W}$ \\
\hline$f_{s}$ & Switching frequency & $60 \mathrm{kHz}$ \\
\hline $\mathrm{Q}$ & $\begin{array}{c}\text { Main switch } \\
\text { (IXFX48N60P) }\end{array}$ & $600 \mathrm{~V}, 48 \mathrm{~A}$ \\
\hline$N_{p}$ & Primary winding & 210 turns \\
\hline$N_{s}$ & Secondary winding & 35 turns \\
\hline $\mathrm{D}$ & diode (B10100) & $100 \mathrm{~V}, 10 \mathrm{~A}$ \\
\hline $\mathrm{R}$ & Load resistance & $6.3 \Omega$ \\
\hline
\end{tabular}

The abbreviated units are: $\mathrm{V}_{\mathrm{DC}}=\mathrm{DC}$ volt, $\mathrm{W}=$ watt, $\mathrm{kHz}=$ kilo Hertz, $\mathrm{mH}=$ milli-henry, $\Omega=$ ohm

Fig. 7 shows a circuit diagram of the single-output flyback converter used for hardware verification in this paper. Ideally, the flux linkage of the coupled-inductor is perfect and the leakage inductances on both sides are insignificant to the main operation. However, since the coupled-inductor contains an air gap between the cores for the flux storage, some flux leakage occurs between the cores or between the windings in practical applications. The leakage is modeled as an inductance, located in series with the ideally-transforming part on both of the primary and the secondary sides.

The leakage inductance becomes a main reason for the severe voltage spikes on the main switch as well as for the electromagnetic interference in terms of the stored energy in the magnetic device. These spikes increase the voltage stress of the main switch, and ultimately decrease the efficiency when the turn-on resistance increases. For these reasons, the flyback converter has been modified by several topological variations through the addition of some peripheral circuits such as a clamping or snubber circuit. However, the fundamental solution is to reduce the leakage inductance even under the significant flux storage operation with a large air gap. This paper applies the coaxial winding method to obtain the ideal operation of the flyback converter through the realization of the minimized leakage inductance [20], [21]. 


\section{B. Experimental Result}

In order to evaluate the performance of the proposed scheme, a $35 \mathrm{~W}$ hardware prototype of the flyback converter has been implemented. The implemented component data concerning the hardware prototype are listed in Table II and a picture of the single-output prototype is presented in Fig. 8. A two channel power analyzer (2802 Xitron Technologies) was used to measure the efficiency of the converter.

Fig. 9 shows the waveforms of the PWM gate signal and the MOSFET's drain-source voltage without a snubber when a conventional sandwich winding coupled-inductor is applied. On the other hand, Fig. 10 shows the waveforms of the PWM signal and the MOSFET's drain-source using the proposed coaxial cable coupled-inductor under the same conditions. From these figures, it can be seen that the ringing of the MOSFET's drain-source voltage with the proposed flyback converter employing the coaxial inductor has been improved significantly from $250 \mathrm{~V}$ to $100 \mathrm{~V}$, which is almost $60 \%$ reduction. The experiment presents good agreement with the analysis and modeling results shown in the previous sections.

Fig. 11 shows the measured efficiency of the hardware prototype according to the input voltage variation. The proposed coaxial method maintains a high efficiency level greater than $83 \%$ in every condition of the input voltage range and with $89 \%$ maximum. Meanwhile, the conventional method presents less than $80 \%$ around the extreme conversion ratios even with the snubbing operation for optimization of the efficiency. From the experimental results, it can be seen that the ideal coupling of the coaxial version has a benefit of the higher conversion efficiency.

For the more detailed analysis, the temperature distributions on the hardware prototypes were measured and presented in Fig. 12. In the experiment, the conventional-type transformer flyback converter and the proposed coaxialwinding transformer flyback converter were investigated. The surface temperatures of the components were measured by a Thermal Imaging Camera (DM-60,Zhejiang Dali Technology Co., Ltd). The infrared thermography system consists mainly of a camera and software for converting the recorded information to the temperature signal [22], [23].

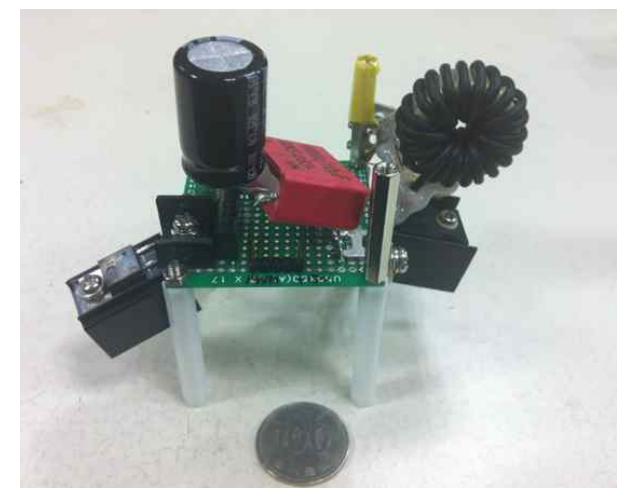

Fig. 8. Photograph of the hardware prototype of the flyback converter.

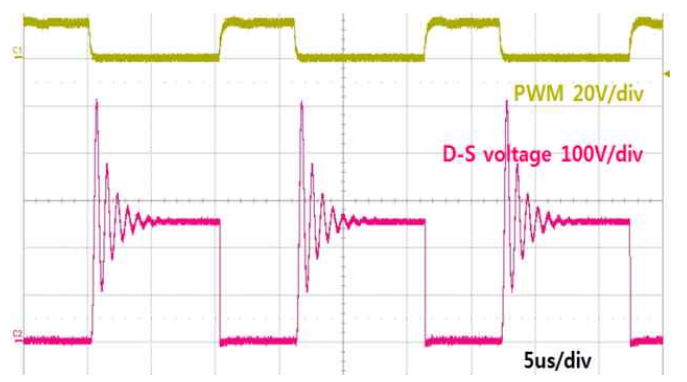

Fig. 9. Waveforms of the hardware experiment using sandwich winding transformer (Top: PWM gating, Bottom: drain-source voltage of main switch).

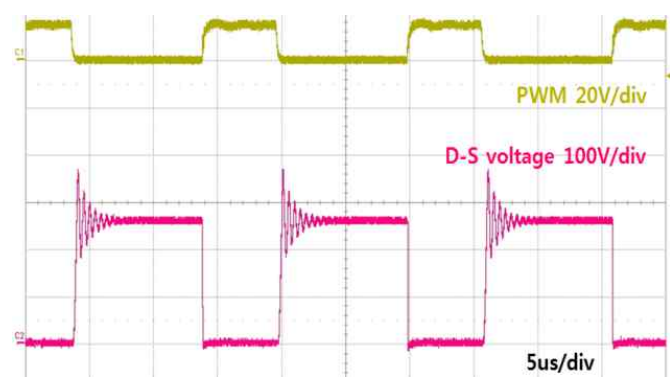

Fig. 10. Waveforms of the hardware experiment using coaxial cable transformer (Top: PWM gating, Bottom: drain-source voltage of main switch).

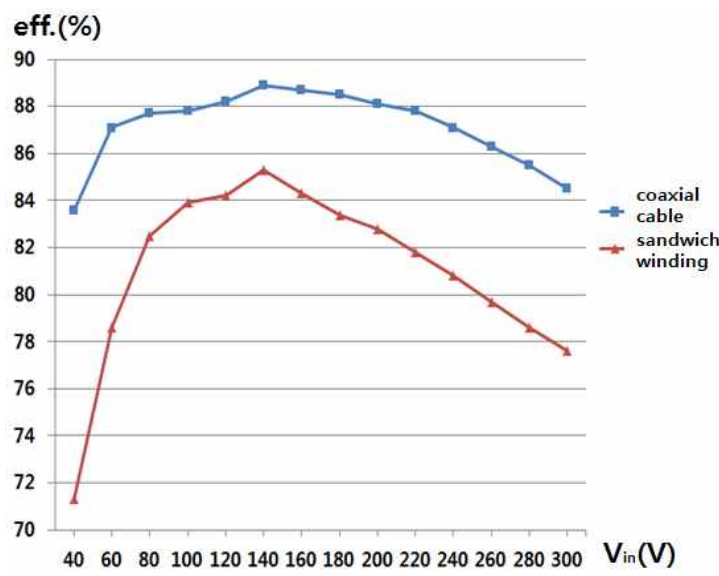

Fig. 11. Experimental results of the single-output flyback converter according to the variation of the input voltage.

Fig. 12(a) and 12(b) show the temperature distributions of the two converters under the same operating conditions such as $140 \mathrm{~V}$ input voltage at full load. The experiment was done at ambient temperature. The thermal images show the spots of heat sources such as the diode, winding and core of the coupled-inductor, and the main switch are shown in dark yellow and outlined rectangles with the numbers 1, 2, 3, and 4 , respectively. The numbers shown in the upper right hand section of the picture are the steady-state operating temperatures measured at each of the rectangular areas. The experimental results show that the diode temperatures are not significantly different from each other, which means that the 
absolute loss-relieving portion at the diode is insignificant. On the other hand, the temperature of the main switch and of the coupled-inductor in the conventional converter rise up to $34.0^{\circ} \mathrm{C}$ and $74.4^{\circ} \mathrm{C}$ (See Fig. 12(a)), while in the proposed case, the temperatures rise to $31.3^{\circ} \mathrm{C}$ and to $29.8^{\circ} \mathrm{C}$ (See Fig. 12(b)). This loss reduction significantly contributes to the efficiency improvement of the proposed converter.

From the experimental results, it can be concluded that the proposed scheme is effective in improving the conversion efficiency, and for relieving the step-down flyback DC-DC converter from severe power stress on the main power-stream components.

\section{Multi-OUtPut Flyback CONVERTER}

\section{A. Multiple Winding Coaxial Transformer}

Fig. 13 shows a circuit diagram of the multiple output flyback converter used for hardware verification in this paper. Multiple output converters are generally composed of a multi-winding transformer due to its easy implementation, simple structure, and low cost. In this paper, it can be supposed that it is possible to extend the single output application of the coaxial winding to the multiple output structure.

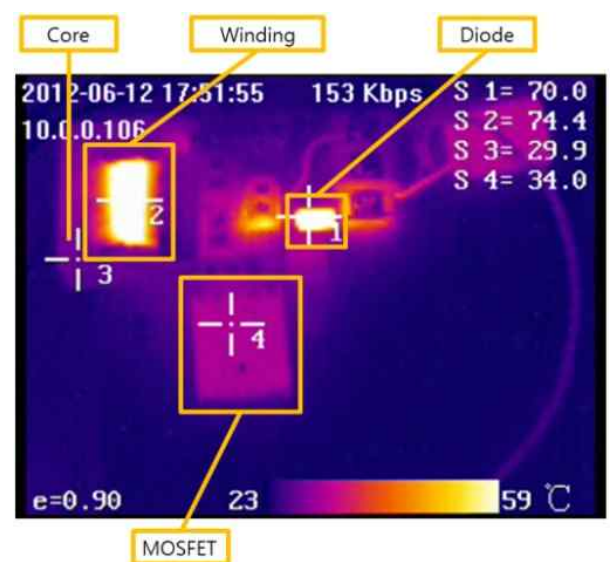

(a) Conventional flyback converter.

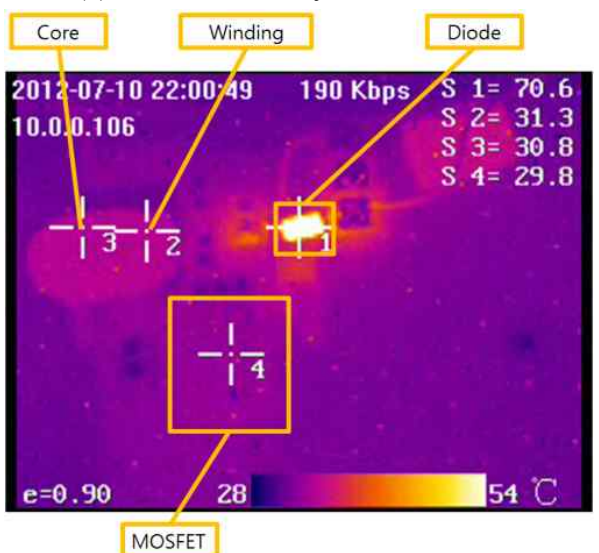

(b) Proposed flyback converter.

Fig. 12. Comparison of thermal distributions of the hardware prototypes $\left(\mathrm{V}_{\text {in }}=140 \mathrm{~V}\right.$, full load). (a) Thermal distribution of the conventional flyback converter. (b) Thermal distribution of the proposed flyback converter.

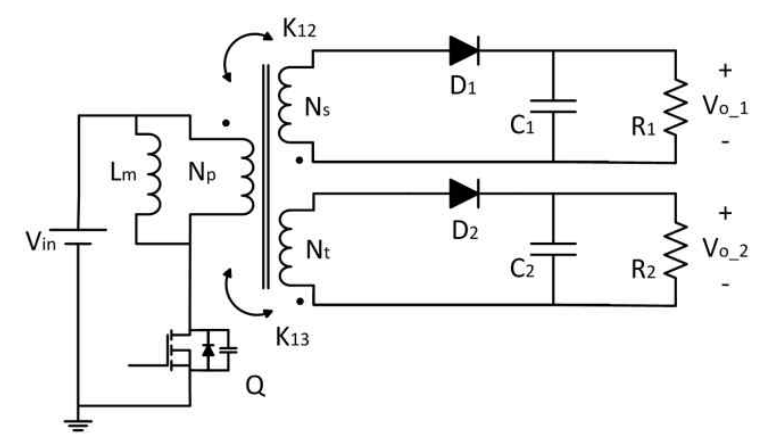

Fig. 13. Circuit diagram of the multi-output flyback converter.

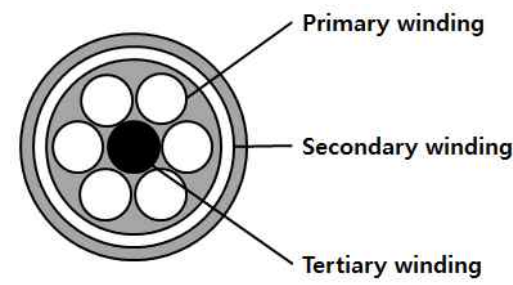

Fig. 14. Cross section of the multiple winding coaxial-cable.

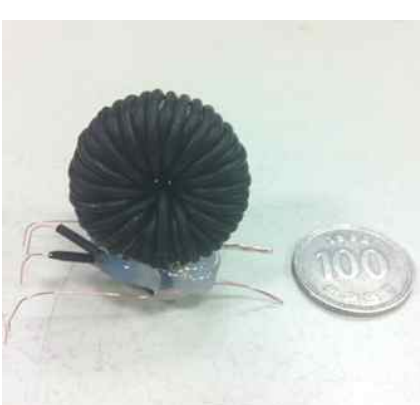

(a) Coaxial cable.

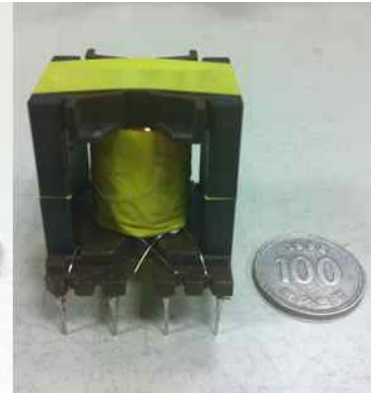

(b) Sandwich winding.
Fig. 15. Three winding sandwich and coaxial-cable transformer.

There can be several structural variations for the realization of the multi-winding coupled-inductor using the coaxial concept. One of them is made with the high-voltage side winding coils and two or more low-side winding coils which cover the high-voltage side winding coils. Another version is where one of the low-side wires is surrounded by multiple strands of high-side wires. Fig. 14 shows a crosssection of the three winding coaxial cable used for the hardware verification of a multi-output flyback converter [24]-[26].

The three winding transformer has two coupling constants. $k_{12}$ is coupling between the primary winding and the secondary winding, and $k_{13}$ is coupling between the primary winding and the tertiary winding (also see Fig. 13).

Pictures of a realized three-winding coaxial-cabled transformer and of a three-winding sandwiched transformer are shown in Fig. 15. The sandwich winding transformer is made of an enamel wire, with a primary winding section of 228 turns and secondary and tertiary windings of 38 turns each. Firstly, the first 114 turns for the primary windings are wound in the innermost layer, and then the second and third 


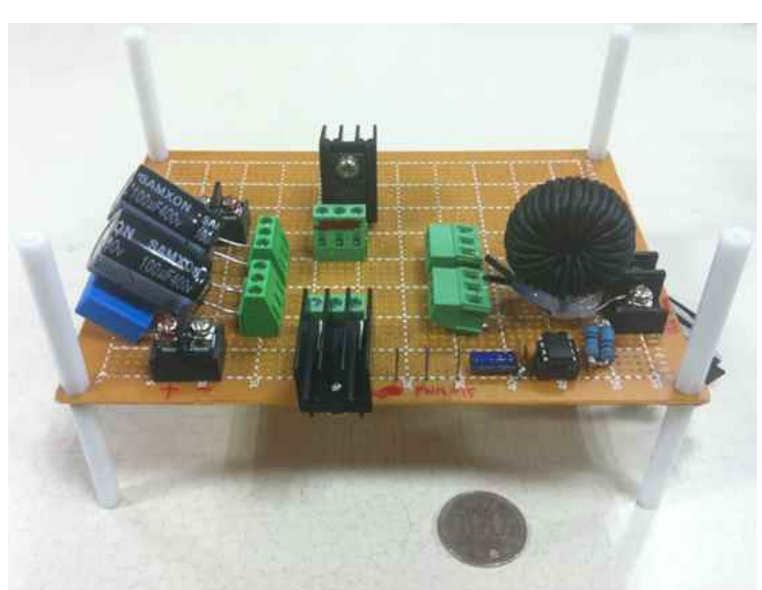

Fig. 16. Photograph of the hardware prototype of the flyback converter.

windings for the secondary and tertiary side of the transformer are wound over the first section of the primary. Finally, the outermost covering is wound for the second section of the primary with the remaining 114 turns to complete the primary winding of 228 turns. PQ3535 core is used for the sandwich winding transformer. The coaxial cable transformer also has the same number of primary, secondary and tertiary turns wound as the $\mathrm{CH} 270125$ toroidal core. The coupling constants of three winding sandwich transformer are $0.9865343\left(k_{12}\right)$ and $0.984723\left(k_{13}\right)$. The coupling constants of the three winding coaxial cable transformer are $0.9999318\left(k_{12}\right)$ and $0.9999282\left(k_{13}\right)$.

TABLE III.

Key Parameters of Flyback CONVERTer

\begin{tabular}{|c|c|c|}
\hline Symbol & Parameter (part number) & Spec. \\
\hline \hline$V_{\boldsymbol{i}}$ & Input voltage & $40-300 \mathrm{VDC}$ \\
\hline$V_{o_{-} 1}$ & Output voltage & $15 \mathrm{VDC}$ \\
\hline$V_{o_{-} 2}$ & Output voltage & $15 \mathrm{VDC}$ \\
\hline$P_{\text {out }}$ & Total output power & $35 \mathrm{~W}$ \\
\hline$f_{S}$ & Switching frequency & $60 \mathrm{kHz}$ \\
\hline $\mathrm{Q}$ & Main switch & $600 \mathrm{~V}, 48 \mathrm{~A}$ \\
\hline$N_{p}$ & Primary winding & 228 turns \\
\hline$N_{s}$ & Secondary winding & $38 \mathrm{turns}$ \\
\hline$N_{t}$ & Tertiary winding & $38 \mathrm{turns}$ \\
\hline$D_{1}$ & Secondary diode (B10100) & $100 \mathrm{~V}, 10 \mathrm{~A}$ \\
\hline$D_{2}$ & Tertiary diode (B10100) & $100 \mathrm{~V}, 10 \mathrm{~A}$ \\
\hline$R_{1}$ & Secondary load resistance & $6.3 \Omega$ \\
\hline$R_{2}$ & Tertiary load resistance & $6.3 \Omega$ \\
\hline
\end{tabular}

The abbreviated units are: $\mathrm{V}_{\mathrm{DC}}=\mathrm{DC}$ volt, $\mathrm{W}=$ watt, $\mathrm{kHz}=$ kilo Hertz, $\mathrm{mH}=$ milli-henry, $\Omega=$ ohm

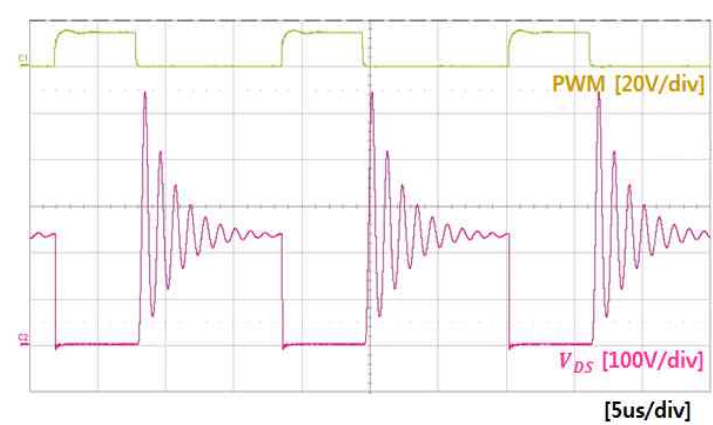

Fig. 17. Waveforms of the hardware experiment using sandwich winding transformer (Top: PWM gating, Bottom: drain-source voltage of main switch).

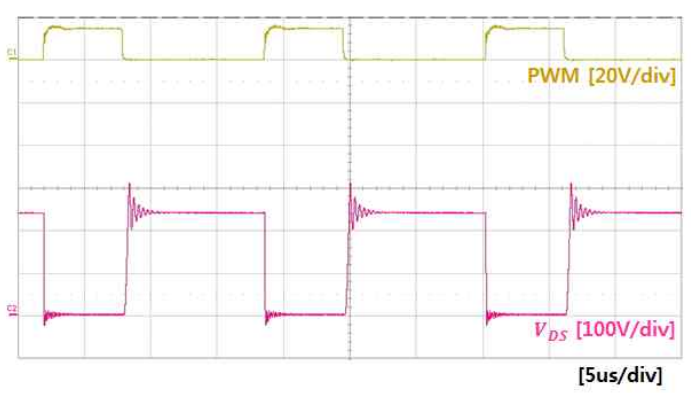

Fig. 18. Waveforms of the hardware experiment using coaxial cable transformer (Top: PWM gating, Bottom: drain-source voltage of main switch).

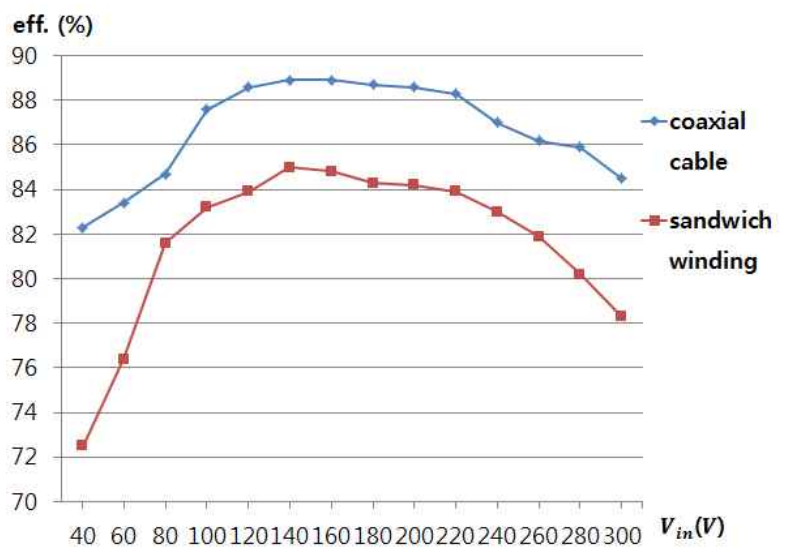

Fig. 19. Experimental results of the multi-output flyback converter according to the variation of the input voltage.

\section{B. Experimental Results}

A $35 \mathrm{~W}$ hardware prototype of the flyback converter has been implemented to verify the higher efficiency of the coaxial cable transformer. The implemented component data concerning the prototype are listed in the Table III and a picture of the multi-output hardware prototype is presented in Fig. 16. The same two channel power analyzer is used to measure the efficiency of the converter.

Fig. 17 shows the waveforms of the PWM gate signal and the MOSFET's drain-source voltage without a snubber using a sandwich winding transformer. Fig. 18 shows the 
waveforms of the PWM gate signal and the MOSFET's drain-source voltage without snubber circuits using the coaxial cable transformer. The ringing of the MOSFET's drain-source voltage has been improved significantly when the coaxial cable transformer is applied. From the results, it can be seen that the coaxial winding method can be successfully applied to multi-winding coupled-inductors.

Fig. 19 shows the overall efficiency of the converter according to the input voltage variation. From the experimental results, it can be seen that the multi output coaxial cable transformer also has a higher efficiency than the conventional sandwich prototype in every condition of the input voltage variation, much like the single-output result.

\section{CONCLUSIONS}

In this paper, a flyback converter using a coaxial-cable transformer for a step-down off-line converter has been proposed. The coupling coefficient of the coaxial cable transformer was measured and presented to be equal to an ideal value, greater than $99.9 \%$. For a more detailed analysis, circuit modeling of the coaxial transformer was done with the help of a frequency response curve obtained from both of secondary open-circuit and secondary short-circuit. $35 \mathrm{~W}$ single-output and multi-output hardware prototypes were tested, under continuous conduction mode with a $60 \mathrm{kHz}$ switching frequency. The experimental results verify that the voltage spike reduction of the drain-source voltage and the power conversion efficiency are superior with the proposed scheme to those of the conventional one by $60 \%$ and $10 \%$, respectively. In addition, the thermal distribution of the conventional and proposed hardware prototypes have been given.

\section{ACKNOWLEDGEMENT}

This work was supported by the Human Resources Development program (No. 20124030200070) of the Korea Institute of Energy Technology Evaluation and Planning(KETEP) grant funded by the Korea government Ministry of Knowledge Economy.

\section{REFERENCES}

[1] J.-H. Park, J.-Y. Ahn, B.-H. Cho, and G-J. Yu, "Dualmodule-based maximum power point tracking control of photovoltaic systems," IEEE Trans. Ind. Electron., Vol. 53, No. 4, pp. 1036-1047, Jun. 2006.

[2] J.-H. Lee, D.-H. Kim, S. Mun, M. T. Nguyen, V. T. Tran, and J.-H. Park, "Series-connected forward-flyback converter for high step-up power conversion," IEEE Trans. Power Electron., Vol. 26, No. 12, pp. 3629-3641, 2011.

[3] R.W. Erickson and D. Maksimovic, Fundamentals of Power Electronics, $2^{\text {nd }}$ Edn., pp. 39-55, John Wiley, New York, USA, 1995.
[4] T. Shimitzu, K. Wada, and N. Nakamura, "Flyback-type single-phase utility interactive inverter with power pulsation decoupling on the DC input for an AC photovoltaic module system," IEEE Trans. Power Electron., Vol. 21, No. 5, pp. 1264-1272, Sep. 2006.

[5] Y.-K. Lo and J.-Y. Lim, "Active-clamping ZVS flyback converter employing two transformer," IEEE Trans. Power Electron., Vol. 22, No. 6, pp 498-501, Nov. 2007.

[6] J.-H. Jung and S. Ahmed, "Flyback converter with novel active clamp control and secondary side post regulator for low standy power consumption under high-efficiency operation," Power Electronics, IET, Vol. 4 No. 9, pp 10581067, 2011.

[7] G. M. L. Chu, D. D. C. Lu, and V. G. Agelidis, "Flybackbased high step-up converter with reduced power processing stages," IET Power Electron., Vol. 5, No. 3, pp. 349-357, Mar. 2012

[8] Z. Liang, R. Guo, J. Li, and A. Q. Huang “A high-efficiency pv module-integrated dc/dc converter for pv energy harvest in freedm systems," IEEE Trans. Power Electron., Vol. 26, No. 3, pp. 897-909, Mar. 2011.

[9] J.-M. Kwon, B.-H. Kwon, and K.-H. Nam, "High-efficiency module-integrated photovoltaic power conditioning system," IET Power Electron., Vol. 2, No. 4, pp. 410-420, Jul. 2009.

[10] Y.-C. Hsieh, M.-R. Chen, and H.-L. Cheng, "An interleaved flyback converter featured with zero-voltage transition," IEEE Trans. Power Electron., Vol. 26, No. 1, pp. 79-84, Jan. 2011.

[11] F. Zhang and Y. Yan, "Novel forward-flyback hybrid bidirectional dc-dc converter," IEEE Trans. Ind. Electron., Vol. 56, No. 5, pp. 1578-1584, May 2009.

[12] M. Taheri, J. Milimonfared, A. Namadmalan, H. Bayat, and M. K. Bakhshizadeh, "Analysis, design and implementation of a new chokeless interleaved zvs forward flyback converter," Journal of Power Electronics, Vol. 11, No. 4, pp. 499-506, Jul. 2011

[13] B.-R. Lin and C.-C. Chien, "Interleaved Boost-Flyback Converter with Boundary Conduction Mode for Power Factor Correction," Journal of Power Electronics, Vol. 12, No. 5, pp. 708-714, Sept. 2012.

[14] V. V. Thang, I. Kim, S. Jeong, M. Kim, and J. Song, "Modeling and investigation of multilayer piezoelectric transformer with a central hole for heat dissipation," Journal of Electrical Engineering \& Technology, Vol. 6, No. 5, pp. 671-676, Sep. 2011.

[15] M. R. Banaei, E. Salary, R. Alizadeh, and H. khounjahan, "Reduction of components in cascaded transformer multilevel inverter using two dc sources," Journal of Electrical Engineering \& Technology, Vol. 7, No. 4, pp. 538-545, Jul. 2012.

[16] D. H. Kim and J. H. Park, "High efficiency step-down flyback converter using coaxial cable transformer," IPEMC 2012-ECCE Asia, Vol. 4, pp. 1855-1858, 2012.

[17] C. G. Kim, "Transcutaneous energy transmission with double-tuned duty-cycle control," Master Thesis, Seoul National University, Feb. 1997.

[18] R. Ridley, "High frequency power transformer measurement and modeling," Power Systems Design Europe, Jan./Feb. 2007.

[19] C.-H. Shon, S.-H. Yi, H.-J. Lee, and D.-S. Kang, "Study on the transfer functions for detecting windings displacement of power transformers with impulse method," Journal of Electrical Engineering \& Technology, Vol. 7, No. 6, pp. 876-883, Nov. 2012.

[20] J. M. Alonso, M. A. Dalla Costa, and C. Ordiz, "Integrated buck-flyback converter as a high-power-factor off-line power supply," IEEE Trans. Ind. Electron., Vol. 55, No. 3, pp. 1090-1100, Mar. 2008. 
[21] W. H. Li, W. C. Li, and X. N. He, "Isolated interleaved flyback-buck converter with inherent clamp scheme," Electron. Letters, Vol. 45, No. 16, pp. 853-854, Jul. 2009.

[22] J.-H. Park and B.-H. Cho, "Nonisolation Soft-Switching Buck Converter with Tapped-Inductor for Wide-Input Extreme Step-Down Applications," IEEE Trans. Circuits Syst. I, Reg. Papers, Vol. 54, No. 8, pp. 1809-1818, Aug. 2007.

[23] J.-H. Park and B. H. Cho, "The zero voltage-switching(ZVS) critical conduction mode(CRM) buck Converter with tapped-inductor," IEEE Trans. Power Electron., Vol. 20, No. 4, pp. 762-774, Jul. 2005.

[24] S. Moisseev, K. Soshin, and M. Nakaoka, "Tapped-inductor filter assisted soft-switching PWM DC-DC power converter," IEEE Trans. Aerosp. Electron. Syst, Vol. 41, No. 1, pp. 174-180, Jan. 2005.

[25] R. Y. Duan and J. D. Lee, "High-efficiency bidirectional DC-DC converter with coupled inductor," IET Power Electron., Vol. 5, No. 1, pp. 115-123, Jan. 2012.

[26] J.-K. Kim, S.-W. Choi, C.-E. Kim, and G.-W. Moon, "A new standby structure using multi-output full-bridge converter integrating flyback converter," IEEE Trans. Ind. Electron., Vol. 58, No. 10, pp. 4763-4767, Oct. 2011.

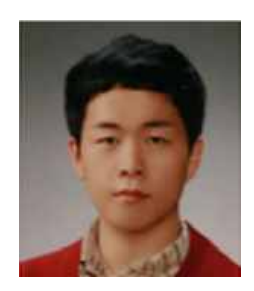

Do-Hyun Kim received his B.S. from the Department of Electrical Engineering of Soongsil University, Seoul, Korea, in 2011. He is currently pursuing his M.S. at Soongsil University. His current research interests include the analysis and design of highfrequency switching converters and renewable energy applications.

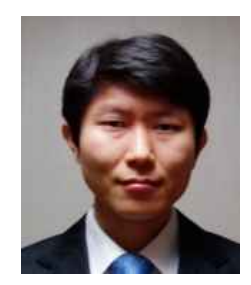

Joung-Hu Park received his B.S., M.S., and $\mathrm{Ph} . D$. from the Department of Electrical Engineering and Computer Science of Seoul National University, Seoul, Korea, in 1999 , 2001 and 2006, respectively. He is currently an Assistant Professor at Soongsil University, Seoul, Korea. His current research interests include the analysis of high-frequency switching converters and renewable energy applications. 